\title{
Zeichnungen aus dem Ersten Weltkrieg von Alfred Schönberner
}

Zu Beginn des Weltkriegsgedenkjahrs 2014 erhielt die Bibliothek für Zeitgeschichte von Frau Dr. Dagmar Langwald, der Enkelin Alfred Schönberners, 29 Bleistiftzeichnungen aus dem Nachlass des Malers als Dauerleihgabe. ${ }^{1}$ und Landschaftsgemälden sowie Ortsansichten seiner Umgebung.

Über den Kriegseinsatz Schönberners ist nichts Näheres bekannt. Aus der Familie wird berichtet, dass er zeitlebens ein entschiedener Kriegsgegner

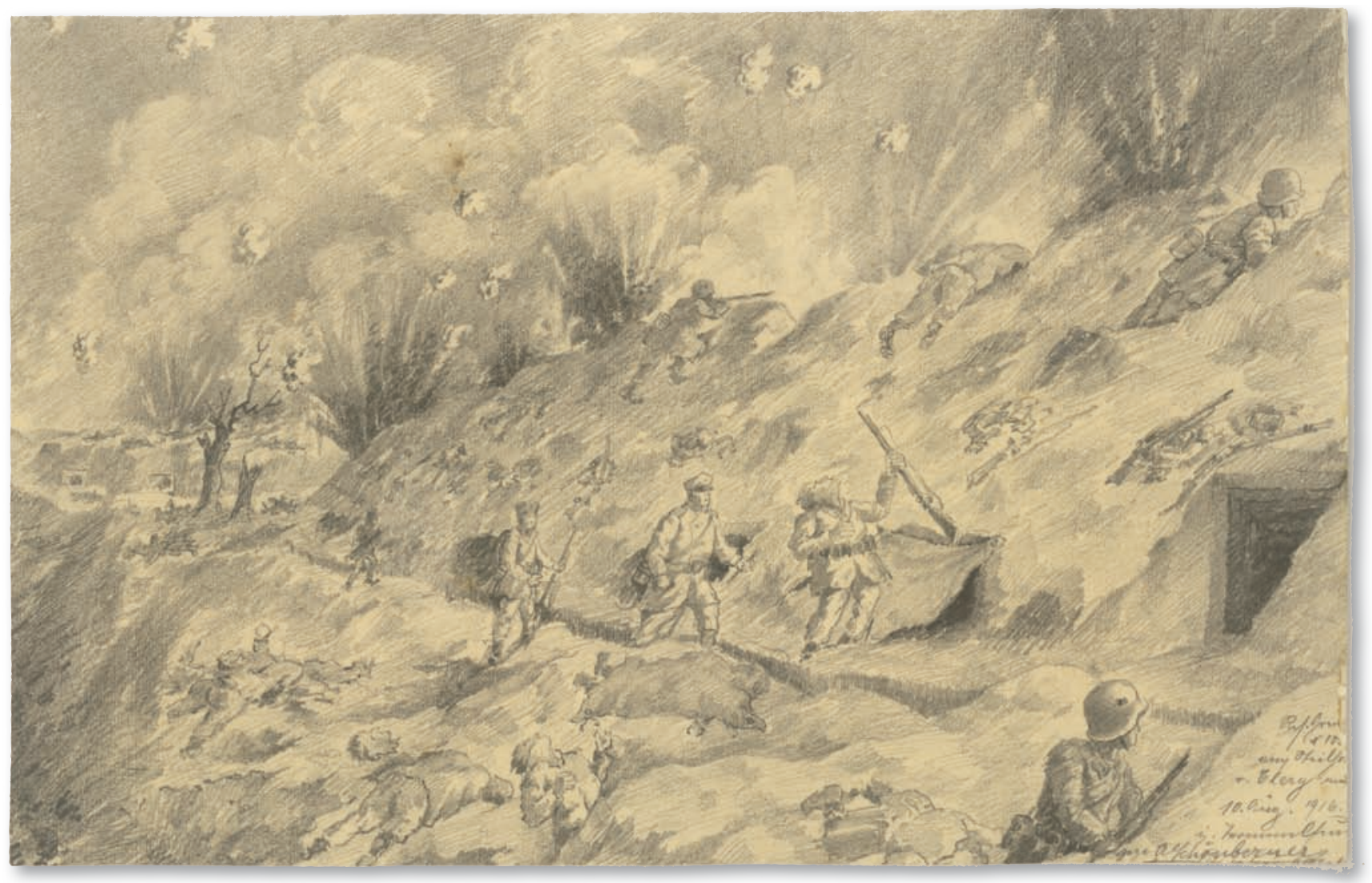

Abb. 1: "Res. Grenadierregiment, Nr 100 am Steilhang von Clery am 10. August 1916 im Trommelfeuer", Signatur: G14.1/2

Alfred Schönberner, geboren 1882 in Seifhennersdorf in der Oberlausitz, kam aus ärmlichen Verhältnissen und absolvierte auf Wunsch seiner Eltern zunächst eine Kaufmannslehre. Den daran anschlieBenden Besuch der Klasse für Musterzeichnen an der Dresdner Kunstgewerbeschule finanzierte er sich durch Auftritte als Klavierspieler in Gaststätten und auf Festveranstaltungen. Vor dem Ersten Weltkrieg arbeitete er in einem Atelier in Dresden und entwarf Muster für Textilien. Als er mit seinem Skizzenbuch in den Ersten Weltkrieg zog, war er verheiratet und hatte eine Tochter. Einen Namen machte sich Schönberner nach dem Krieg mit Natur- war, der sich für die Errichtung von Denkmälern für die Kriegstoten engagierte. Ihm selbst soll sein stets mitgeführtes Skizzenbuch das Leben gerettet haben, das tödliche Geschoss blieb im Buchblock stecken. Das Skizzenbuch mit dem Einschussloch hat sich im Nachlass des Künstlers erhalten.

Bei den 29 der Bibliothek für Zeitgeschichte anvertrauten Zeichnungen handelt es sich um meist datierte, mit erläuternden Titeln versehene Arbeiten aus dem Jahr 1916. Vermutlich gehörte Schönberner dem sächsischen Grenadier-Reserve-Regiment Nr. 100 an. Auf einer Skizze (Abb. 1) zeigt er das

(1) Sämtliche Zeichnungen des Konvoluts wurden in das Internetportal europeana1914-1918 eingestellt und können dort eingesehen und heruntergeladen werden: www.europeana1914-1918.eu/de/contributions/12551 


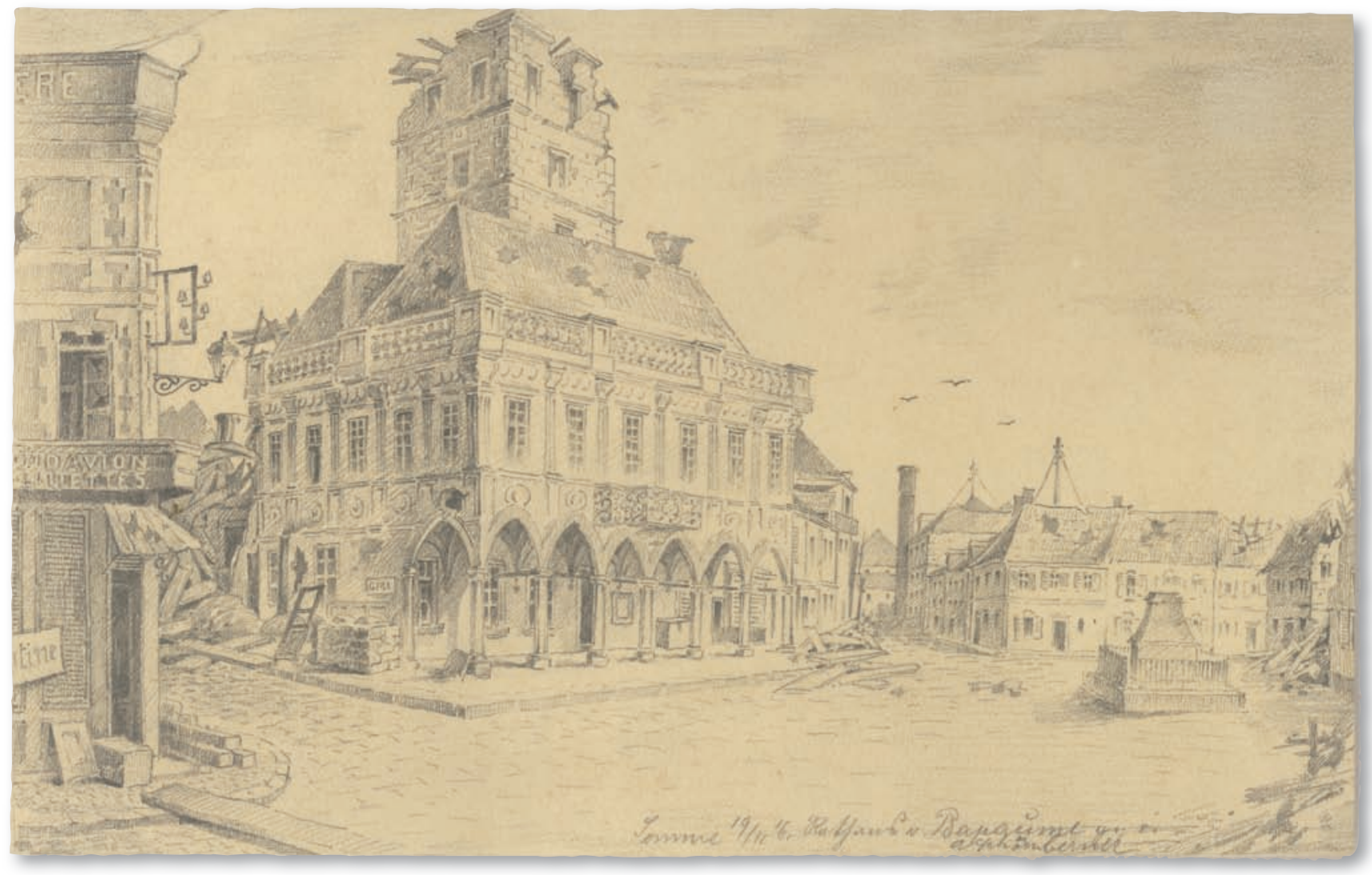

Abb. 2: "Somme 19.11.16. Rathaus v. Bapaume", Signatur: G14.1/22

Regiment unter Beschuss, "im Trommelfeuer" des 10. August 1916: explodierende Granaten, Soldaten, deren Körper getroffen von einem Geschoss nach hinten gerissen werden, andere die bereits gefallen sind. Ein notdürftig abgedeckter Leichnam versperrt den wenigen, verloren wirkenden Kämpfern den Weg. Das Bild hat nichts Heroisches, eher scheint hier die Wehrlosigkeit der Gruppe abgebildet. Ein am Boden liegender abgerissener Kopf und die ebenso achtlos verstreuten Gewehre unterstreichen die apokalyptische Szenerie. Es ist das dramatischste Bild dieses Konvoluts. Weitere 19 Blätter halten in detaillierten Zeichnungen den Alltag an der Westfront fest: im Schützengraben, im Unterstand, auf Posten. Acht Zeichnungen bilden den Kriegsschauplatz ab. Zerstörte Dörfer sind zu sehen, zerschossene Häuser und menschenleere Straßen (Abb. 2). Auf einem einzigen Bild scheint die Welt noch in Ordnung - ein Idyll, eine kleine unversehrte Kirche in der Champagne. Ein Sujet, das er in vielen seiner Heimatbilder nach dem Krieg wieder aufgreifen wird.

Die Bibliothek für Zeitgeschichte dankt sehr für die Bereicherung ihrer Sammlungen!

Irina Renz 